\title{
Implicit Self-Theories for the Effects of Envy Types on Unique Product Choice: An Abstract
}

\author{
Valeriia Kaptceva and Nara Youn
}

\begin{abstract}
We investigated how individuals with growth or fixed mind-sets react to the experiences of malicious and benign envy and what kind of influence these interactions have on consumers' unique product choice behaviors. By doing so, we tried to provide better understanding and the full connection between two different envy types and unique product choice. In this work, we are putting a small addition to the theory (and practical implication) of envy by considering an important role of belief on our personality, that is, the implicit self-theories.

Results of the first study showed that people tend to choose a unique product in the malicious envy condition, while a person primed with benign envy is more likely to choose a standard product. The results of the second study showed that implicit self-theories moderate the observed effect. When a person experiences malicious envy and has an entity mind-set, his or her desire for a unique product or distinction from the envied person increases.

The final study sheds light on multiple serial mediation roles of entity mind-set and desire for uniqueness for the effect of malicious envy on unique product choice (i.e., selection of a product that the envied other does not have) and incremental mind-set and desire for self-improvement for the effect of benign envy on standard or similar product choice (i.e., selection of a product that the envied other has).
\end{abstract}

References Available Upon Request

V. Kaptceva $\cdot$ N. Youn $(\bowtie)$

Hongik University, Seoul, South Korea

e-mail: velpodnebesnaya@yandex.ru; nara@hongik.ac.kr

(C) Academy of Marketing Science 2019 